\section{Andamios Revista de Investipación Social}

Andamios. Revista de Investigación Social ISSN: 1870-0063

revistaandamios@uacm.edu.mx

Universidad Autónoma de la Ciudad de México México

Serrano Gómez, Enrique

Teoría de la Constitución, positivismo y derechos fundamentales

Andamios. Revista de Investigación Social, vol. 9, núm. 18, enero-abril, 2012, pp. 59-87

Universidad Autónoma de la Ciudad de México

Distrito Federal, México

Disponible en: http://www.redalyc.org/articulo.oa?id=62823326004

Cómo citar el artículo

Número completo

- Más información del artículo

- Página de la revista en redalyc.org

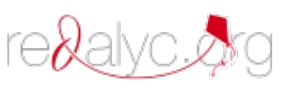

Sistema de Información Científica

Red de Revistas Científicas de América Latina, el Caribe, España y Portugal

Proyecto académico sin fines de lucro, desarrollado bajo la iniciativa de acceso abierto 


\title{
Teoría de la Constitución, positivismo Y DERECHOS FUNDAMENTALES
}

\section{Enrique Serrano Gómez*}

\begin{abstract}
Resumen. En la historia del constitucionalismo conviven dos nociones de constitución: una descriptiva y otra prescriptiva. La primera remite a la experiencia empírica de las constituciones; la segunda a lo que la constitución debería ser. El presente trabajo presenta una interpretación que utiliza ambas nociones, tanto en el análisis empírico, como en la reflexión teórica, a fin de entender con mayor claridad algunos de los principales problemas a los que debe responder una Teoría general de la constitución: a) cómo reconciliar la diversidad empírica de constituciones; b) en qué sentido una constitución debe ser considerada como un elemento que expresa la racionalización y la autonomía del sistema jurídico, y c) defender la idea de que una constitución vigente en nuestra época debe garantizar los derechos fundamentales.

Palabras Clave. Constitución, positivismo, Estado, derechos fundamentales, norma fundamental.
\end{abstract}

\section{CONSTITUCIÓN: SENTIDOS DESCRIPTIVO Y PRESCRIPTIVO}

Desde la perspectiva de Giovanni Sartori la definición formal de constitución dada por el positivismo, esto es, la definición que se limita a caracterizar a la constitución como el conjunto de normas que determinan la forma de Estado (cualquiera que ésta sea), representa una

\footnotetext{
* Doctor en Filosofía, Universidad de Constanza (Alemania). Profesor-investigador, Departamento de Filosofía, Universidad Autónoma Metropolitana (UAm)-Iztapalapa. Correo electrónico: eserranog@axtel.net
} 
deformación del significado de este concepto, a tal grado, que ha destruido su razón de ser. Según él, el significado históricamente correcto de constitución denota "una estructura de la sociedad política, organizada a través de y mediante la ley, con el objetivo de limitar la arbitrariedad del poder y de someterlo al derecho" (Sartori, 1992: 20). Se trata de un reproche que con frecuencia se hace al positivismo jurídico. Me parece que se trata, hasta cierto punto, de una crítica injusta, pues, si se revisa la historia del constitucionalismo, siempre ha existido la conciencia de que el término "constitución" puede ser utilizado en dos sentidos: prescriptivo y descriptivo. Por ejemplo, Montesquieu reconoce que si unas constituciones tienen por objeto la libertad política de los ciudadanos, otras sitúan su fin en la gloria del Estado; lo cual significa que no todas las constituciones se adecuan a un mismo sistema de valores.

La crítica de Sartori resulta válida para aquellas modalidades de positivismo jurídico que consideran que el sentido descriptivo es el único aceptable en la teoría del derecho. Sin embargo, el proyecto original del positivismo - piénsese en Bentham o incluso en el propio Austinno era desechar el significado prescriptivo, sino darle prioridad al descriptivo. En la medida que se pueda mantener la clara diferenciación de niveles, dicho proyecto puede sacar a la luz un aspecto muy importante de las constituciones modernas.

Max Weber sostiene que el Estado moderno, a diferencia del Estado estamental ligado al feudalismo, tiene el carácter de instituto (Anstalt), es decir, una organización cuyas normas han sido racionalmente estatuidas y tienen la pretensión de valer para todo aquél que reúna determinadas características externas (nacimiento, estancia, utilización de determinados servicios, etcétera), con independencia de si entró o no por decisión personal, o si colaboró o no en la elaboración de esas normas. Ahora bien, de inmediato Weber advierte que un derecho puede ser racional en muy diversos sentidos, de acuerdo con las diferentes direcciones seguidas por el desenvolvimiento de la práctica y del pensamiento jurídico en cada contexto social (Weber, 1983: 509). ${ }^{1}$ Por

\footnotetext{
1 "Es posible racionalizar la vida desde diferentes puntos de vista y en las direccio-
} nes más diversas. Esta sentencia, olvidada con frecuencia, debería encabezar los 
tanto, ante todo, es preciso establecer el carácter que tiene el proceso de racionalización del derecho en el mundo occidental moderno. Para ello distingue entre: a) racionalidad con arreglo a fines, en la cual se buscan los medios más adecuados para acceder a un fin dado (fin-medio); y b) racionalidad con arreglo a valores, en la que se busca adecuar la conducta de manera consciente a un valor, simplemente por la creencia en los méritos de ese valor (norma-caso). En abstracto, estos dos tipos de racionalidad no se oponen; por el contrario, se complementan, como es el caso cuando la elección de los fines se realiza conforme a valores.

Sin embargo, en el nivel empírico puede surgir una tensión o contradicción entre estas modalidades de racionalidad, cuando para el actor los valores o los intereses que definen los fines o ambos adquieren una validez absoluta. Ello da lugar a la dicotomía racionalidad formal y racionalidad material. Mientras esta última implica la exigencia de adecuarse al valor, con independencia de las circunstancias concretas en que se realiza la acción y las consecuencias que ella tiene, la racionalidad formal asume el imperativo de acceder a un fin, con independencia de los valores, es decir, de los otros valores diferentes al implícito en el fin. La racionalidad formal tiene un carácter técnico, lo cual implica, además, el desarrollo de la actividad del cálculo. El paradigma de la racionalidad formal se encuentra en la economía mercantil (el hombre económico), la cual, en su estado puro, erige en fin absoluto a la ganancia, haciendo a un lado otros valores, entre ellos el de la justicia distributiva.

La racionalidad formal y la material (cualquiera que sea el valor que la oriente) discrepan en principio en toda circunstancia, aunque sean numerosos los casos empíricos en que coinciden $[\ldots]$. Pues la racionalidad formal del cálculo en dinero no dice nada sobre la naturaleza de la distribución de los medios naturales [...]. Las racionalidades

estudios sobre el racionalismo. El racionalismo es un concepto histórico que encierra un mundo de contradicciones" (Weber, 1983: 62). "Una entidad no es irracional en sí misma, sino en relación a un determinado punto de vista racional. Si alguna utilidad tendrá este estudio será mostrar el concepto de racionalidad, aparentemente unívoco, en su complejidad" (1983: 86). 
material y formal (en sentido de una calculabilidad exacta) se separan cabalmente entre sí en forma tan amplia como inevitable. Esta irracionalidad fundamental e insoluble de la economía es la fuente de toda problemática social y en especial de todo socialismo (Weber, 1983: 83, 85). ${ }^{2}$

Weber sostiene que una de las características centrales de la modernidad es la expansión de la racionalidad formal, propia del mercado, a otras esferas de la sociedad, entre ellas a la esfera de la política y, en especial, al Estado. Esto da lugar al fenómeno histórico del mercantilismo, esto es, la organización del Estado como una empresa, lo cual tiene como uno de sus efectos más notables el convertir a su cuadro administrativo en un sistema burocrático. ${ }^{3}$ Pero también la racionalidad formal, a través del Estado, invade al sistema jurídico. Esa racionalización se manifiesta en diversos aspectos: 1) la superación de los rasgos tradicionales y mágicos que dominaban los procedimientos del derecho germánico medieval, para dar lugar a procedimientos de indagación, en los que, a través de pruebas y testimonios, se busca acceder a una descripción verdadera de los hechos, que respalde la sentencia; 2) el desarrollo de instituciones especializadas y la formación de un grupo de profesionales (consolidación de un sistema jurídico autónomo); 3) la superación de un sistema casuístico, para dar paso a un sistema de normas generales, 4) la sistematización del derecho, lo cual implica someterlo a la exigencia de la coherencia y, en general, de la validez lógica.

\footnotetext{
${ }^{2}$ La irracionalidad de la economía mercantil aparece cuando se la contempla desde la racionalidad con arreglo al valor de la justicia distributiva. Por eso, ya Adam Smith advertía de la necesidad de limitar la competencia mercantil mediante un sistema institucional que responda a dicho valor. Evidentemente esta tensión entre racionalidades es la fuente de las demandas de la tradición socialista.

3 "La administración burocrática pura, o sea, la administración atenida al expediente, es a tenor de toda la experiencia la forma más racional de ejercer una dominación; y lo es en los sentidos siguientes: en precisión, continuidad, disciplina, rigor, confianza (por tanto en posibilidad de calcular para el soberano y los interesados), aplicación universal del formalismo a toda suerte de tareas y susceptibilidad de perfeccionamiento técnico para alcanzar el óptimo de sus resultados" (Weber, 1983: 178). Me he permitido hacer algunas correcciones a la traducción.
} 
De acuerdo con esta perspectiva sociológica, la constitución es el producto de este proceso de racionalización formal del derecho, pues en ella se reúnen las normas superiores del sistema jurídico, esto es, aquellas que lo identifican al determinar la forma de Estado y la manera en que se ejerce el poder del gobierno, así como la producción, modificación y derogación de las normas jurídicas. Sin duda, esto es un aspecto fundamental de las constituciones propias de los estados modernos. Incluso, si se profundiza en este análisis sociológico se advertirá que la racionalización del derecho, que hace posible la codificación constitucional, es, a su vez, un efecto del proceso de diferenciación funcional de la sociedad que da lugar a la autonomía del sistema jurídico. Esto es lo que ha resaltado la teoría de Niklas Luhmann, al afirmar que la constitución presupone un sistema jurídico que, al procesar los conflictos, opera de manera autónoma (Luhmann, 1993).

A partir de su objetivo descriptivo, lo primero que quiere destacar la tradición teórica del positivismo es que la constitución, considerada como un elemento que expresa la racionalización y la autonomía del sistema jurídico, es compatible con cualquier régimen y contenido. Una constitución vigente en una sociedad particular que no garantiza los derechos fundamentales, no deja de ser una constitución. El reconocimiento de la diversidad empírica, a partir de su pretensión científica, es una aportación indiscutible del positivismo jurídico. Sin embargo, una vez aceptada la multiplicidad de constituciones que se encuentran en la experiencia y que se constata que no todas ellas se ajustan a las exigencias del constitucionalismo, de inmediato se percibe que ese aspecto formal, esa supuesta definición neutral, no es suficiente para caracterizar el concepto de constitución, ya que para comprender la diversidad de constituciones se requiere apelar a los principios del constitucionalismo. Dicho de otra manera, la definición formal del positivismo únicamente destaca lo que tienen en común las constituciones modernas, pero sus diferencias sólo pueden determinarse por el grado de proximidad o alejamiento de los principios constitucionalistas.

Según esta interpretación que propongo, el objetivo no es elegir entre una noción descriptiva y una noción prescriptiva de constitución, sino utilizar ambas; tanto en el análisis empírico, como en la reflexión 
teórica. Cabe señalar que el argumento en el que he sustentado dicha propuesta se basa en la tesis de Gustav Radbruch (extraída, a su vez, de la teoría kantiana del derecho), a saber: toda descripción del derecho (lo que el derecho es) presupone, de manera implícita o explícita, una comprensión del sentido social del derecho (lo que el derecho debe ser). En este caso, se puede decir que la adecuada descripción de la diversidad de constituciones implica entender el sentido que históricamente se ha ligado a la idea de constitución. Sartori tiene la razón al sostener que la noción garantista precede, histórica y lógicamente, a la noción formal de constitución.

Además, me parece que esta propuesta no es ajena al positivismo jurídico, sino que en la discusión que se dio en el interior de esta tradición teórica se arribó a la misma propuesta o, por lo menos, a una conclusión muy cercana a ella. Esto se puede percibir al examinar la polémica entre dos titanes que llevaron al positivismo, por rumbos diferentes, más allá de los límites establecidos en un principio. Me refiero a la polémica entre Hans Kelsen y Carl Schmitt; pero, para apoyar la tesis respecto a que la propuesta que se ha hecho aquí no es externa al desenvolvimiento del positivismo, resulta interesante la postura que asumen Hermann Heller y Karl Loewenstein a partir de esa confrontación teórica.

La Teoría pura del derecho empieza por distinguir entre la constitución en sentido lógico-jurídico y la constitución en sentido jurídico-positivo. Para comprender esta distinción es preciso recordar que para Kelsen el derecho es un sistema jerárquico, en el cual la validez de una norma se encuentra en una norma superior, que determina las condiciones para establecer normas inferiores. ${ }^{4}$ Esta cadena de validez, que configura la estructura jerárquica del ordenamiento jurídico, culmina en una norma fundamental, la cual, según Kelsen, aunque no es formulada de manera expresa, está constituida por el imperativo siguiente: debes obedecer a la constitución y a todas las leyes emanadas de ella. La tesis que encierra la noción de norma fundamental consiste en afirmar que

4 "Las normas de cada grado superior delimitan — como elemento de su contenidoun hecho, que constituye creación del Derecho en su grado inferior. Para que el proceso jurídico avance, precisa realizar realmente el hecho determinado por la norma superior" (Kelsen, 1979: 326). 
en una comunidad en la que, tanto las normas constitucionales como las que emanan de ellas, son más frecuentemente obedecidas que desobedecidas, los individuos que ajustan su conducta a la normatividad positiva, asumen, de manera implícita, esa norma superior.

Es muy importante subrayar que la validez de la norma fundamental no se reduce a la eficacia; esta última es el fenómeno empírico que permite asumir, de manera justificada, la existencia de esa norma en dicha comunidad, es decir, la eficacia es la ratio cognoscendi de la norma fundamental. Pero la validez de esa regla depende de la creencia de los individuos, esto es, de que los miembros de la comunidad consideren, mediante su práctica, a las normas positivas como instancias que deben obedecer. Me parece que otra manera más clara de decir esto consiste en afirmar que la norma fundamental remite a la autoridad del sistema de normas positivas. Desde esta perspectiva, si bien la eficacia es lo que permite conocer la existencia de la norma fundamental (ratio cognoscendi), la norma fundamental es, a su vez, aquello que explica, en gran medida, la eficacia de la normatividad jurídica (una de las ratio essendi de la eficacia). Por supuesto que la eficacia de la normatividad jurídica también depende de la amenaza de coacción, ello es el rasgo distintivo del derecho, pero esta última no es suficiente. Si fuera el caso de que todos los miembros de la sociedad obedecieran al derecho por miedo a la coacción, se tendría que preguntar de inmediato: ¿por qué lo obedecen? Hay que asumir que por lo menos un grupo reducido considera que obedecer al derecho es un deber. Cuanto mayor es la autoridad del derecho, menor es la necesidad de actualizar la coacción y a la inversa.

La constitución en sentido lógico jurídico (yo diría trascendental) es, por tanto, dicha norma fundamental. La constitución en su sentido jurídico-positivo remite al conjunto de normas superiores de un sistema jurídico particular. El carácter superior de esas normas se debe a que ellas definen los órganos del Estado y, con ello, regulan la producción, modificación y derogación de las normas generales inferiores. Aunque Kelsen describe al derecho como un sistema normativo dinámico, admite que una constitución, en sentido jurídico-positivo, puede llegar a determinar también el contenido de las normas inferiores, al prescribir o excluir ciertos contenidos. Sería el caso de las constituciones que 
incluyen un catálogo de derechos fundamentales. Sin embargo, considera que esto no es un requisito necesario para hablar de una constitución, lo estrictamente esencial de una constitución es regular la producción de normas. Es decir, para él lo esencial de la constitución se encuentra solamente en lo que he llamado su aspecto formal.

Esa norma [la norma fundamental] constituye la constitución en sentido lógico-jurídico, cuando instituye un órgano creador del Derecho. Y la constitución en sentido jurídico-positivo surge como un grado inmediatamente inferior en el momento que dicho legislador establece normas que regulan la legislación misma. Sin embargo, la constitución, esto es, el hecho de constituir un orden jurídico estatal, fundamentando su unidad, consiste en la norma fundamental hipotética no positiva, que es lo que hemos llamado constitución en sentido lógico-jurídico, pues sobre dicha norma se basa el primer acto legislativo no determinado por ninguna norma superior del Derecho positivo (Kelsen, 1979: 325-326).

A partir de la noción de constitución en su sentido jurídico-positivo, Kelsen distingue, a su vez, entre constitución en sentido material, esto es, la norma o normas positivas que regulan la producción de las normas jurídicas generales, y la constitución en sentido formal, esto es, el documento solemne que contiene (por lo menos en gran parte) el conjunto de normas superiores del orden jurídico. Estados Unidos de Norteamérica fue la primera nación que estableció una constitución en sentido formal; mientras que Gran Bretaña carece de una constitución en sentido formal, por lo que en ella la constitución en sentido material tiene el carácter de derecho consuetudinario y, por consiguiente, no hay diferencia formal entre las leyes constitucionales y las ordinarias.

La existencia de una forma especial para las leyes constitucionales, o forma constitucional, se debe a la Constitución en sentido material. Si existe una forma constitucional, entonces las leyes constitucionales tendrán 
que ser distinguidas de las ordinarias. La diferencia consiste en que la creación, y esto significa la promulgación, la reforma y la abrogación de las leyes constitucionales es más difícil que la de las ordinarias. Existe un procedimiento especial, una forma determinada para la creación de las constitucionales, diferente del procedimiento de creación de las ordinarias. Esa forma especial relativa a las constituciones, forma constitucional o Constitución en sentido formal de la palabra, no es indispensable, mientras que la Constitución material, es decir, las normas que regulan la creación de preceptos generales y -en el derecho moderno- las que determinan a los órganos y el proceso de la legislación, constituyen un elemento esencial de cada orden jurídico (Kelsen, 1995: 147). ${ }^{5}$

Respecto a la constitución en sentido lógico, esto es, la norma fundamental, Kelsen afirma que sólo contiene el deber de obedecer a la legalidad, pero no presupone ningún contenido. ${ }^{6}$ Este es el punto en que se va a enfocar la crítica de Carl Schmitt, pues para él la noción de imperio de la ley, inherente a la idea de constitución, implica ya un contenido, el cual remite a los valores propios de la burguesía. Imperio de la ley significa, ante todo, lo contrapuesto al imperio de los hombres, esto es, en oposición a las formas de gobierno en las que el legislador se sitúa por encima de la ley (legibus solutus), el imperio de la ley exige que el legislador debe quedar vinculado a su propia ley, con lo que su facultad de legislar no se transforma en un medio para el ejercicio arbitrario del poder. Si bien esta caracterización del núcleo

\footnotetext{
${ }^{5}$ Según esto, lo esencial de la constitución en sentido formal no es el documento solemne en sí mismo, sino la instauración de un procedimiento diferente, más complejo, para las leyes constitucionales.

6 "La norma fundamental (que no sólo es admisible, sino necesaria para la ciencia del Derecho) no tiene ningún contenido absoluto ni relativo, sino que se orienta hacia el material cuya interpretación como unidad jurídica constituye su función exclusiva; por eso, la autoridad suprema creadora de Derecho puede serlo lo mismo el autócrata que el pueblo, pero el contrato social del jusnaturalismo posee un contenido absoluto" (Kelsen, 1979: 308).
} 
del ideal de Estado de derecho es impecable, desde la perspectiva de este autor, dicho ideal sólo se puede concebir desde un concepto idealizado de la ley:

La vinculación del Legislador a la Ley es posible, sin embargo, sólo en tanto la Ley es una norma con ciertas propiedades: rectitud, razonabilidad, justicia, etc. Todas estas propiedades presuponen que la Ley es una norma general [...]. La burguesía, en lucha por su libertad y su Estado de Derecho adoptó aquí un concepto de Ley que descansa en una vieja tradición europea y que pasó desde la filosofía griega, a la Edad Moderna, a través de la Escolástica: Ley no es la voluntad de uno o de muchos hombres, sino una cosa general-racional; no voluntas, sino ratio (Schmitt, 1988: 150). ${ }^{7}$

En este texto se torna explícita la tesis central de la crítica de Schmitt, a saber: el ideal del Estado de derecho sólo puede sustentarse en los presupuestos de la tradición iusnaturalista. En un primer momento, Carl Schmitt interpreta la noción de norma fundamental de la Teoría pura como un simple subterfugio para ocultar los presupuestos iusnaturalistas en los que ella se sustenta. A pesar de que existen algunas observaciones aisladas del propio Kelsen que podrían respaldar esta crítica, me parece que se trata de una interpretación equivocada. Sin embargo, hay que reconocer que al no ofrecer una explicación más clara y precisa de la norma fundamental, el mismo Kelsen propicia este cuestionamiento. Para poder analizar con más cuidado la confrontación entre Kelsen y Schmitt, abordaré antes las críticas de este último al iusnaturalismo moderno, con el cual se justificó teóricamente al Estado de derecho.

Describir a los derechos fundamentales como atributos que poseen los seres humanos con independencia del orden civil al que pertenecen, es decir, como cualidades que cada ser humano tiene por

\footnotetext{
7 "Para la concepción del Estado de Derecho, la Ley es, en esencia, norma, y una norma con ciertas cualidades: regulación jurídica (recta, razonable) de carácter general. Ley, en el sentido del concepto político de Ley, es voluntad y mandato concretos, y un acto de soberanía" (Schmitt, 1982: 155).
} 
el mero hecho de serlo, presupone la existencia de un orden natural de cuyo conocimiento se pueden deducir las normas que deben guiar las acciones. Contra esta tesis tradicional del iusnaturalismo, Schmitt sostiene que las leyes dependen en todos los casos de una voluntad (para que algo valga, alguien lo tiene que hacer valer). En el Estado moderno, la ley surge como un acto de aquél o aquellos que ejercen el poder soberano: ley en un Estado de principio monárquico es la voluntad del rey; ley, en una democracia, es la voluntad del pueblo: lex et quod populus jussit. La ley no vale en virtud de sus cualidades morales y/o lógicas, sino vale como mandato: Auctoritas, non veritas facit legem. Para Schmitt el uso de los presupuestos iusnaturalistas por parte del liberalismo no sólo encierra un error teórico, una falsa descripción de la normatividad jurídica, sino que implica, ante todo, una estrategia política, la cual tiene como objetivo sustituir la soberanía concreta por un ideal, a saber, el de la soberanía de la ley. Desde su perspectiva, una parte importante de esta estrategia política es reservar el nombre de "constitución" sólo para aquellas constituciones que, mediante un sistema de pesos y contrapesos, garanticen lo que él califica como libertad burguesa: libertad personal, propiedad privada, libertad de contratación, libertad de industria y comercio, etcétera.

La terminología de la lucha política comporta el que cada partido en lucha reconozca como verdadera Constitución sólo aquella que se corresponda con sus postulados políticos. Cuando los contrastes de principios políticos y sociales son muy fuertes, puede llegarse con facilidad a que un partido niegue el nombre de Constitución a toda Constitución que no satisfaga sus aspiraciones. En particular, la burguesía liberal, en su lucha contra la Monarquía absoluta, puso en pie un cierto concepto ideal de Constitución, y lo llegó a identificar con el concepto de Constitución. Se hablaba, pues, de Constitución sólo cuando se cumplían las exigencias de libertad burguesa y estaba asegurado un adecuado influjo político de la burguesía. De esta forma surge un concepto singular, distintivo, de Constitución. Así, cada Estado no tiene ya 
por sí mismo una Constitución, sino que hay Estados con y sin Constitución, Estados constitucionales y Estados no constitucionales (Schmitt, 1982: 58).

Schmitt es de la opinión que en realidad nunca se pudo compaginar la soberanía estatal y las exigencias constitucionales. Para él, las constituciones liberales tuvieron como efecto negar la soberanía estatal, lo cual conduce a la muerte del Leviatán. Hay que recordar que en la metáfora orgánica de Hobbes la soberanía representa el alma del Estado; un Estado en el que la soberanía no reside en una voluntad concreta, aquella que toma las decisiones políticas fundamentales (es soberano quien decide el estado de excepción), carece de la vitalidad para gobernar; la constitución de la República de Weimar es, desde su óptica un ejemplo de esta situación.

El esfuerzo de un consecuente y cerrado Estado de Derecho va en el sentido de desplazar el concepto político de Ley para colocar una soberanía de la Ley en el lugar de una soberanía existente, concreta, esto es, dejar sin respuesta la cuestión de la soberanía, y por determinar la voluntad política que hace de la norma adecuada un mandato positivo vigente [...]. El elemento propio del Estado de Derecho, con dos principios: derechos fundamentales (como principio de la participación) y división de poderes (como principio orgánico), no implica, considerado en sí mismo, forma de gobierno alguna, sino sólo una serie de límites y controles del Estado, un sistema de garantías de la libertad burguesa y de la relativización del poder del Estado (Schmitt, 1982: 155, 201).

Su narrativa sobre la agonía del Estado es la siguiente: el Estado gubernativo (Regierungsstaat), esto es, el Estado clásico europeo (en nuestros términos el Estado Absolutista), modelo de la unidad política, el cual conquistó el más asombroso de todos los monopolios, el de la decisión política (soberanía centralizada), esa joya de la forma europea y del 
racionalismo occidental que instauró la paz en el interior de la nación, fue destronado por el Estado legislativo (Gesetzgebungstaat). Éste último, producto de la revoluciones modernas, se caracteriza por la división de los poderes; sobre él, dice Schmitt, que ya no hay poder soberano, ni mero poder, porque quien ejerce uno u otro actúa en nombre de la ley. Posteriormente, aparece el Estado jurisdiccional (Jurisdiktionsstaat), en el que el poder de los jueces pretende llenar el vacío de la soberanía. Por último, aparece el Estado administrativo (Verwaltungsstaat), el cual se distingue por la consolidación de un poder impersonal, que actúa a través de medidas, es decir, ordenanzas de carácter objetivo, las cuales encuentran su justificación en cada situación concreta. Dicha modalidad de Estado corresponde a lo que Weber llamó la jaula de hierro, producto de la burocratización del mundo (la expansión de la racionalidad formal), en la cual se encuentra en riesgo la supervivencia de cualquier tipo de libertad.

En contraste con la narrativa liberal, en la cual se considera que la expansión del Estado es lo que pone en peligro la libertad, Schmitt sostiene que la ampliación de la esfera estatal lejos de representar su poder, es un síntoma de su decadencia. Para él, la omnipresencia del Estado denota su impotencia. Un Estado que carece de la fuerza para gobernar genera una gran cantidad de instituciones, con la vana esperanza de responder adecuadamente a la pluralidad de demandas que provienen de la sociedad. Lo que sucede es que una multiplicidad de poderes intermedios que carecen de un control legal, provenientes en su mayoría del ámbito económico, se apoderan de las entrañas del Estado. El problema reside en que entre esos poderes no existe una coordinación, lo que tiene por efecto producir una situación que recuerda al estado de naturaleza que describe Hobbes. El siglo xx y su Estado total no significan el triunfo de lo político, sino la plena hegemonía de lo económico y su racionalidad formal, técnica, en donde la guerra lejos de desaparecer, simplemente pierde su sentido político, para convertirse en un asunto técnico (la destrucción del enemigo absoluto), motivado por la crematística. Se trata del renacimiento de las guerras justas, pero ahora con una máscara económico-humanista. 
Hoy no existe nada más moderno que la lucha contra lo político. Banqueros americanos, técnicos industriales, marxistas y revolucionarios anarco-sindicalistas se unen en la exigencia de que la unilateral dominación política sobre la imparcialidad de la vida económica sea superada. La exigencia de que sólo deben existir tareas técnicasorganizativas y económicas-sociológicas, pero no más problemas políticos (Schmitt, 1991: 98). ${ }^{8}$

Situados en los albores del siglo xxi, la narrativa de Schmitt resulta, sin duda, atractiva. Es claro que la época de la estatalidad ahora toca a su fin, en el sentido del Leviatán que se alza por encima de las colinas de la sociedad civil, para gobernarla. Ya no es posible pensar al Estado-nación como una cúspide o un centro, que tiene la facultad de controlar la compleja dinámica de las sociedades. Todas las teorías políticas y jurídicas que se construyeron a lo largo de cuatro siglos bajo el presupuesto de la existencia de una soberanía (poder absoluto), tienen que ser sometidas a una crítica radical. Los retos inéditos que se enfrentan en la actualidad, anuncian un tiempo propicio para una filosofía política que sea capaz de distanciarse de los presupuestos teóricos tradicionales. Sin embargo, el carácter sugerente de dicha narrativa no debe impedir ver que se trata de una construcción teórica que encierra una gran cantidad de problemas.

En primer lugar, aparece un problema empírico fundamental. Schmitt, al describir la dinámica del siglo xx, tiene la esperanza de resucitar al Leviatán. Esa esperanza se fundamenta en la falsa e ingenua

\footnotetext{
8 "Un dominio sobre seres humanos que reposa sobre un fundamento económico, si se mantiene apolítico, en el sentido de sustraerse a toda responsabilidad y supervisión políticas, tiene que aparecer justamente como un terrible engaño [...]. Y si los explotados y sometidos intentan defenderse en la situación en la que se encuentran, es evidente que no podrán hacerlo con medios económicos. No menos evidente es, sin embargo, que quienes detentan el poder económico considerarán cualquier intento extraeconómico de modificar su posición de poder como un acto de violencia criminal, y que intentarán impedirlo. Pero, claro está, que con esto se derrumba aquella construcción ideal de una sociedad que reposaría sobre el intercambio y los contratos recíprocos y que sería, por eso mismo, pacífica y justa" (Schmitt, 1991: 105).
} 
creencia de que es posible responder efectivamente a los problemas de una sociedad compleja mediante una simplificación de la estructura institucional del sistema político (volver al Estado gubernativo). Con ello pasa por alto las advertencias que hacía Weber en su conferencia sobre el Socialismo (Weber, 1982): una centralización del poder, lejos de suprimir la jaula de hierro, la torna más asfixiante (ahí no se teje la dictadura del proletariado, sino la dictadura del funcionario). Además, a la luz de la experiencia del espectacular derrumbe de los regímenes socialistas, se puede afirmar que la centralización de la soberanía lejos de fortalecer el poder estatal, propicia su debilidad. La aspiración de reconstruir una instancia central que sirva como instrumento para enfrentar los intrincados retos contemporáneos, no sólo resulta reaccionaria, sino completamente alejada de las circunstancias que imperan en la actualidad.

La creencia en que mediante un Estado con una soberanía centralizada se puede imponer un orden en las caóticas sociedades modernas, conduce a Schmitt a considerar que el Führer es la instancia que debe defender la constitución, frente a la pluralidad de poderes sociales. En contraste con esta posición, Kelsen asume la diferenciación funcional que caracteriza a la estructura de las sociedades modernas y, por tanto, considera que a la complejidad de la realidad social sólo se puede responder incrementando la complejidad del sistema institucional. De ahí su propuesta respecto a que la constitución debe ser defendida por un tribunal constitucional:

Dado que precisamente en los casos más importantes de violación de la Constitución, Parlamento y Gobierno son partes en causa, se aconseja llamar para decidir sobre la controversia a una tercera instancia [Tribunal constitucional] que esté fuera de esa oposición y que bajo ningún aspecto sea partícipe del ejercicio del poder que la Constitución distribuye en lo esencial entre Parlamento y Gobierno. Que esa misma instancia reciba por ello un cierto poder es inevitable. Pero hay una gran diferencia entre confiar a un órgano ningún otro poder que no sea la función de control de la Constitución y reforzar el poder 
de uno de los portadores del supremo poder mediante la atribución ulterior del control de la Constitución (Kelsen, 1995: 54). ${ }^{9}$

Por otra parte, la propuesta de que el Führer (un titular del poder ejecutivo con poderes dictatoriales) debe ser el defensor de la constitución, se sustenta en la tesis de que la validez y con ella la autoridad del orden legal puede reducirse a la voluntad del titular de la soberanía centralizada. Presupuesto que, como ya se vio, fue cuestionado de manera radical por Kelsen, ya que no sólo implica un tránsito ilegítimo entre el ser y el deber ser (la validez de una norma sólo puede encontrarse en una norma superior), sino que implica reducir la legalidad a un mandato del soberano, lo cual impide explicar la autoridad propia del derecho. Dicho en los términos de Kelsen, en la propuesta de Schmitt, se reduce el sentido objetivo de la legalidad al sentido subjetivo, lo cual conduce a explicar la obediencia únicamente por la amenaza de coacción, esto es, a describir al derecho como simples órdenes de un bandido. Además, en este punto, se puede acudir al argumento clásico respecto a que, una legalidad que depende de la arbitrariedad de un individuo o de un grupo particular, carece de una forma definida, es decir, carece de una constitución.

La respuesta contundente de Kelsen, orilló a que Schmitt modificara su propuesta inicial, al plantear que la decisión política no es la fuente de la legalidad, sino únicamente la mediación entre el orden concreto de la sociedad y el orden normativo del derecho. En cierta manera, lo que hace Schmitt es recuperar la distinción de Ferdinand Lassalle entre constitución real y constitución como hojas de papel, ${ }^{10}$ que se remonta al mundo greco-latino clásico. Con ello se pone en tela de juicio

\footnotetext{
9 Schmitt considera que el mayor peligro para el orden constitucional proviene del Parlamento, ya que los diputados son presas más fáciles de los llamados poderes intermedios de la sociedad. Si bien esto es, hasta cierto punto cierto, pensar en el carácter neutral del poder ejecutivo contradice la experiencia de la historia política de las sociedades.

10 "He aquí, pues, señores, lo que es, en esencia, la Constitución de un país: la suma de los factores reales de poder que rigen en ese país [...]. Así, pues, todo país tiene, y ha tenido siempre, en todos los momentos de su historia, una Constitución real y verdadera.
} 
la pretensión de pureza de la teoría de Kelsen, porque se destaca que la descripción adecuada no sólo de la constitución, sino de todo el ordenamiento jurídico, requiere el que sean situados en su contexto social. Dicho con otras palabras, en una teoría del derecho deben complementarse, sin perder la diferenciación entre los niveles del ser y el deber ser, lo que Kelsen denomina la jurisprudencia normativa y la jurisprudencia sociológica. Por tanto, más allá de sus profundas diferencias ideológicas, no se trata de elegir entre la postura teórica de Kelsen y la de Schmitt, sino de unificarlas. Esto es lo que entendieron dos importantes representantes de la teoría del derecho: Hermann Heller y Karl Loewenstein. Sobre este asunto el primero de ellos afirma:

Cabe, por eso, distinguir en toda Constitución estatal, y como contenidos parciales de la Constitución política total, la Constitución no normada [la normalidad, el orden concreto] y la normada, y dentro de ésta, la normada extrajurídicamente [la costumbre] y la que lo es jurídicamente. La Constitución normada por el derecho conscientemente establecido y asegurado es la Constitución organizada [...]. La Constitución estatal, así nacida, forma un todo en el que aparecen complementándose recíprocamente la normalidad y la normatividad, así como la normatividad jurídica y la extrajurídica (Heller, 1981: 269, 273).

Para extraer las posibilidades que encierra este proyecto teórico es indispensable no perder de vista que la exigencia de situar a la constitución en su contexto con el objetivo de caracterizar las relaciones que se establecen entre el sistema de normas constitucionales y el orden concreto de la sociedad no implica negar la autonomía del sistema jurídico. De ahí, que sea necesario resaltar que dicha autonomía no significa aislamiento, sino cierre operacional, es decir, que sólo el sistema

Lo específico de los tiempos modernos - hay que fijarse bien en esto, y no olvidarlo, pues tiene mucha importancia - no son las Constituciones reales y efectivas sino las Constituciones escritas, las hojas de papel" (LaSalle, 2002: 92, 101). 
jurídico puede determinar qué es y no es derecho. Por lo que no es posible considerar que la constitución sea un mero reflejo del orden concreto de la sociedad. Un primer ejemplo de las posibilidades teóricas de dicho proyecto se encuentra en el libro Teoría de la constitución de Loewenstein, quien utiliza la distinción entre normas constitucionales y orden concreto de la sociedad para desarrollar una clasificación que nos permite aproximarnos a la diversidad empírica. El primer paso de este autor es analizar lo que él llama esquemas anticuados de clasificación de las constituciones:

1) La distinción entre las constituciones que están contenidas en un documento formal y aquellas que no lo están. Según Loewenstein este esquema pasa por alto que prácticamente todos los estados poseen hoy una constitución escrita, a excepción de Gran Bretaña y Nueva Zelanda. Además agrega que, a pesar de que en la Gran Bretaña se ha desdeñado la unificación de sus convenciones constitucionales en un documento escrito, sí existe una cierta articulación del orden legal fundamental. La diferencia de esta última es que la racionalización formal del derecho se basa en la inducción, esto es, a partir de casos concretos (la iuris prudentia). Sin embargo, como señala Zagrebelsky, detrás de este esquema se encuentra una diferencia que no se puede perder de vista: mientras en la Europa continental rige la concepción de la ley como producto de la voluntad política soberana, el rule of law británico presupone que el derecho se origina a partir de experiencias sociales concretas, es decir, el derecho no es un producto estatal, sino social.

Estas contraposiciones reflejan los modelos iniciales, pero han cambiado muchas cosas al hilo de una cierta convergencia entre los dos sistemas. Desde el siglo pasado, el rule of law se ha transformado en la souvereignity of Parliament, lo que indudablemente ha aumentado el peso del derecho legislativo, sin llegar a suplantar el common law, como testimonia el hecho de que en Gran Bretaña no existan códigos, en el sentido continental. Pues bien, aunque hoy en día no sea posible formular contraposiciones tan claras como las que se acaban de señalar, éstas sirven para esclarecer los caracteres originarios del Estado de 
Derecho y mostrar la existencia de alternativas basadas en concepciones no absolutistas de la ley (Zagrebelsky, 2007: 27). ${ }^{11}$

2) Otro esquema anticuado es el que, con base en la mecánica del procedimiento para enmiendas constitucionales, distingue entre constituciones flexibles y rígidas. Sobre esto Loewenstein señala que la Constitución de los Estados Unidos de Norteamérica, supuestamente rígida en tanto el procedimiento de enmienda constitucional es deliberadamente complicado, en la práctica se ha transformado notablemente, entre otros factores, por la interpretación de la Suprema Corte. En cambio, la flexible Constitución británica, que puede cambiarse a través de una ley ordinaria, se ha mantenido relativamente estable. Me parece que hoy existe un amplio consenso en que más que una dicotomía o distinción radical, se tiene que hablar de grados de flexibilidad o de rigidez; lo cual representa un tema fundamental.

3) Uno más de los esquemas tradicionales de clasificación se refiere a los tipos de gobierno que se establecen en las constituciones. Ello nos conduce a la distinción clásica entre formas de gobierno monárquicas y republicanas. Evidentemente esta clasificación no es suficiente, pues, en su simplicidad nos llevaría a situar, por ejemplo, a Gran Bretaña y Suecia en la misma categoría que Arabia Saudita y Nepal. Sin embargo, creo que se podría mantener este esquema siempre y cuando se tomen más elementos de la llamada Ingeniería Constitucional.

4) Por último se encuentra la clasificación en la que se distinguen entre organizaciones estatales federales y unitarias (centralistas). De acuerdo con Loewenstein, aunque este criterio ha conservado más valor que los otros, también ha perdido utilidad debido a que el principio federal ha sufrido una progresiva erosión. Sobre este tema cabe una discusión más amplia, la cual trasciende los marcos del presente trabajo.

Como se puede apreciar, los que Loewenstein llama esquemas anticuados de clasificación de las constituciones no pueden desecharse

\footnotetext{
${ }^{11}$ A pesar de cierta convergencia entre las tradiciones, la diferencia entre ambas juega actualmente un papel importante, como se verá al abordar el tema de los derechos fundamentales.
} 
por completo. Pero sí es cierto que requieren de modificaciones importantes para adquirir de nuevo una utilidad en el trabajo empírico. Frente a las clasificaciones tradicionales, su propuesta empieza por introducir dos criterios de clasificación:

1) Constituciones originarias y derivadas. Una constitución originaria es aquella que introduce un principio funcional nuevo u original, como por ejemplo el parlamentarismo británico; el sistema presidencial americano; el constitucionalismo francés de 1793 con su tipo de gobierno por asamblea, el cesarismo plebiscitario de las constituciones napoleónicas. Las constituciones derivadas, por tanto, son aquellas que siguen o imitan uno de los principios de las constituciones originarias.

2) Constituciones ideológico-programáticas y utilitarias. Las primeras son aquellas constituciones cargadas ideológicamente o que poseen un programa ideológico. Su ejemplo son las constituciones liberales que asumen el telos del constitucionalismo clásico de limitar el poder político para garantizar el derecho de los ciudadanos. Por constituciones utilitarias entiende aquellas constituciones ideológicamente neutrales. Un caso ejemplar de esto sería la Constitución Federal de Bismarck (1871), en la cual se regulan las relaciones entre los órganos estatales superiores, pero no existe en ella una referencia a los derechos fundamentales. Sobre esta clasificación es posible preguntar: ¿existen realmente constituciones ideológicamente neutras? El propio Loewenstein apunta que detrás de la Constitución de Bismarck existe una concepción autoritaria del poder político. Una constitución que se limita a regular la organización de los órganos estatales, sin mencionar derechos fundamentales, toma de manera implícita una posición ideológica. Una vez que introduce estos dos criterios Loewenstein afirma:

Las anteriores sugerencias que tendían más bien a desentrañar la esencia y el contenido de las constituciones y no su mecanismo externo, pueden ser útiles para una clasificación realista, pero sufren el mismo defecto fundamental que las categorías tradicionales clásicas. Fallan justamente al no tomar en cuenta un hecho que, en tiempos recientes, ha cambiado de manera decisiva la significación de la constitución escrita. Si al principio, 
un documento constitucional formal servía para limitar el ejercicio de poder político en interés de la libertad de los destinatarios del poder, la existencia hoy de una constitución escrita no implica, en absoluto, ipso facto una garantía de distribución y, por tanto, limitación del poder. Cada vez con más frecuencia, la técnica de la constitución escrita es usada conscientemente para camuflar regímenes autoritarios y totalitarios. En muchos casos, la constitución escrita no es más que un cómodo disfraz para la instalación de una concentración del poder en las manos de un detentador único. La constitución ha quedado privada de su intrínseco telos: Institucionalizar la distribución del ejercicio del poder político (Loewenstein, 1976: 213-214). ${ }^{12}$

Existen casos en donde la constitución muestra ostensiblemente su carácter autoritario, como la Constitución de Haile Selassie (1931), que en su artículo 5 establece: en el Imperio Etíope el poder supremo yace en el emperador. En otras ocasiones, la constitución retoma los principios del constitucionalismo, pero en la práctica no regulan realmente el ejercicio del poder. Se trata de meras fachadas que ocultan la manera en que realmente se ejerce el poder. La constitución es, simplemente, hojas de papel, ajenas a su realidad social. Por ello, Loewenstein sostiene la necesidad de una clasificación ontológica de las constituciones, entendida como una clasificación que asume como principio básico la relación entre la normatividad jurídica y el orden concreto de la sociedad. En lugar de analizar la esencia y el contenido de las constituciones, el criterio del análisis ontológico radica en la concordancia de las normas constitucionales con la realidad del proceso del poder. Así, se tiene la siguiente clasificación:

1) La constitución normativa. Se trata de la constitución que no sólo posee una validez formal, sino se encuentra viva, es decir, se relaciona con el orden concreto de la sociedad a través de las convicciones y

\footnotetext{
12 "En la mitad del siglo xx, la autocracia iza con ironía la falsa bandera de la democracia. La constitución es, para decirlo con Shakespeare, sólo una rosa para cualquier nombre".
} 
conductas de los ciudadanos. Dicho de otra manera, en la sociedad existe una cultura política (cívica), producto de un largo proceso de aprendizaje, que proporciona efectividad a las normas constitucionales. La coacción es un refuerzo de la legalidad, pero su vigencia depende de un consenso práctico sobre su validez. Para usar una expresión de la vida diaria: la constitución es como un traje que sienta bien y que se lleva realmente.

2) La constitución nominal. Es una constitución que si bien posee validez jurídica, no se adapta a la dinámica real del proceso político. Esta modalidad de constitución es propia de aquellas sociedades donde se ha implementado el constitucionalismo sin que exista una cultura política que corresponda a sus exigencias. La vigencia de la normas no se encuentra respaldada por un proceso histórico que permita a los ciudadanos ver a los derechos como conquistas de la sociedad. Generalmente estas constituciones son un producto de la actividad de una élite política y/o intelectual desvinculada de las creencias hegemónicas de su contexto social. De hecho, normalmente los miembros de la clase política son los primeros que no respetan la normatividad constitucional, por lo que resulta difícil exigir a los ciudadanos que guíen su conducta por ella. Latinoamérica es un ámbito geográfico que ofrece una multiplicidad de ejemplos de esta situación. La esperanza que encierra la constitución nominal es que algún día disminuya el abismo que existe entre la normatividad y la realidad social. Y para continuar con el símil: el traje cuelga cierto tiempo en el armario y será puesto cuando el cuerpo nacional haya crecido.

3) La constitución semántica. Es una constitución meramente organizativa, es decir, establece la organización de los órganos del Estado, pero no limita el ejercicio del poder político. Aunque es plenamente aplicada, se trata de una constitución que simplemente expresa una situación de dominio; la presencia de una clase política que no ha dejado de ser un conjunto de bandidos estacionarios. Ejemplo de ello es la mencionada constitución del Imperio Etíope o la concepción estalinista de la constitución, en la cual se plasma la conformación de un poder existente, ajeno a controles efectivos. Manteniendo el símil: el traje no es en absoluto un traje, sino un disfraz. 
Lowenstein admite que la clasificación de las constituciones que él ofrece no es más que un primer intento que requiere ser corregido conforme se avance en las investigaciones empíricas. ${ }^{13}$ Pero con independencia de las correcciones que se puedan sugerir a esta clasificación ontológica de las constituciones lo importante es destacar que los trabajos de Heller y Loewenstein muestran que es posible mantener el reconocimiento de la especificidad de la dimensión normativa del derecho y, al mismo tiempo, ofrecer una explicación de la dinámica de este último mediante el estudio de su relación con el orden concreto de la sociedad.

Después de la Segunda Guerra Mundial se acusó al proyecto del positivismo jurídico de ser cómplice, consciente o inconsciente, de lo que Loewenstein llama la perversión de la constitución a través de la autocracia moderna. Me parece que este tipo de críticas son fácilmente refutables, ya que la estrategia que utilizó el totalitarismo del siglo xx para eludir los controles constitucionales del poder político, más que ser positivista, tenía un carácter iusnaturalista. En contra de la tesis respecto a que la validez de la legalidad depende de que ésta garantice las condiciones para acceder a un consenso libre, las diferentes formas de totalitarismo apelaron a una supuesta verdad que trasciende la voluntad de los seres humanos. Recuérdese la jerarquía racial, esto es, natural, de la que hablaban los nazis o el orden histórico en el que se apoyaba el discurso estalinista.

El problema del positivismo consistió en que su estrecha concepción de la ciencia le permitió realizar una crítica al iusnaturalismo, pero no dar cuenta del sentido social de la noción de constitución. De esta manera, dejó el terreno libre a la ofensiva del autoritarismo. Por ejemplo, en su polémica con Schmitt, Kelsen parece conceder a su oponente la razón, porque concluye que, en última instancia, todo depende de una

13 Giovanni Sartori propone denominar constituciones nominales a las llamadas por Loewenstein constituciones semánticas ("Las constituciones nominales son, por lo tanto, nominales en el sentido que se apropian del nombre constitución") y constituciones fachada a las constituciones nominales ("Las constituciones fachada son diferentes de las nominales en cuanto toman la apariencia de verdaderas constituciones. Lo que las hace pseudo-constituciones es que éstas no son observadas, al menos en lo que respecta a sus características garantistas fundamentales"). Véase "Constitución", en Sartori (1992). 
elección personal entre la concepción científica y la seductora seguridad de las ideologías. Sin embargo, su rígida pretensión de pureza le impidió percibir que tanto su concepto de norma fundamental, como su defensa desencantada (no iusnaturalista) de la democracia ofrecían elementos para explicar y justificar los derechos fundamentales. Para recuperar las aportaciones del positivismo a una teoría de la constitución, sin admitir sus debilidades, basta destacar que los individuos sólo pueden adquirir el deber de obedecerla si ella asume el objetivo de garantizar su libertad (sus derechos fundamentales), mediante un sistema de pesos y contrapesos con el cual se limite la arbitrariedad en el ejercicio del poder. Pero, como ha hecho patente Loewenstein, asumir la noción prescriptiva de constitución no impide reconocer la diversidad de constituciones que se encuentran en el nivel empírico. Por el contrario, el contraste entre lo que la constitución deber ser y lo que las constituciones son, abre tanto un campo de la reflexión teórica, como una orientación de la práctica política.

\section{CONSTITUCIÓN Y DERECHOS FUNDAMENTALES}

En este trabajo me he esforzado por destacar algunas de las contribuciones del positivismo jurídico a la teoría del derecho constitucional. Sin embargo, antes de terminar, es menester subrayar un error de esta tradición. En contra de las posturas iusnaturalistas, las distintas versiones del positivismo han insistido en que todas las normas jurídicas son un artificio humano. Pero han pasado por alto que afirmar que el derecho y la constitución son productos culturales implica asumir que estos tienen un sentido (el fin para el que fueron creados). Sentido que debe ser comprendido antes de poder aspirar a describir y explicar de manera correcta la dinámica del sistema jurídico. En relación con este problema, Gustav Radbruch advierte lo siguiente:

El derecho es obra humana, y como toda obra humana sólo puede ser comprendida a través de su idea [...]. Una consideración ciega para el fin, es decir, para el valor, es, pues imposible ante una obra humana, y por consiguiente 
lo es también una consideración ciega al valor del derecho o de cualquier fenómeno jurídico aislado [...]. El derecho sólo puede comprenderse en el círculo de la conducta impregnada de valor (Radbruch, 2003: 11).

Trátese de describir una licuadora o un automóvil o una mesa sin hablar de los fines para los que fueron creados. Sin duda se podrá ofrecer una descripción muy detallada de su apariencia; pero al faltar la comprensión de su función, siempre será incompleta. En distintas versiones del positivismo se sostiene que la función del derecho es coordinar las acciones o estabilizar expectativas. A pesar de ello no existe una comprensión del sentido del derecho, porque al mantenerse en una consideración ciega al valor, se cree que dicha función se realiza únicamente a través de la amenaza de coacción, lo cual es falso. Sin duda la amenaza de coacción es un rasgo distintivo del ordenamiento jurídico, el cual es, además, una variable indispensable para explicar su eficacia. Pero el principal factor que da razón de esa eficacia es que las normas jurídicas, a diferencia de la simple amenaza de coacción que emite un delincuente, se presentan ante los individuos como instancias revestidas de autoridad.

Retomo ahora la mencionada distinción, propuesta por Kelsen, entre el sentido lógico-jurídico y el sentido jurídico-positivo del concepto de constitución. De acuerdo con éste último, la constitución se encuentra conformada por el conjunto de normas superiores del ordenamiento jurídico en las que se define la organización del poder político y con ello se establecen los procedimientos (se otorgan potestades) para crear las normas inferiores. A partir de este sentido se podrá desarrollar una descripción muy detallada de todos los elementos que componen su estructura, pero no es posible acceder a la comprensión de la función que tiene esa instancia suprema del ordenamiento jurídico. Para lograr este objetivo es necesario acudir al sentido lógico-jurídico. De hecho, en contraste con lo que afirma Kelsen, no se trata de dos sentidos distintos del concepto de constitución, sino que, como se verá, remiten a dos dimensiones del mismo concepto.

Como he señalado, el llamado sentido lógico-jurídico denota la norma fundamental (Grundnorm). Mucho se ha discutido sobre este aspecto 
central de la Teoría pura del derecho, pues el propio Kelsen no lo explica con precisión y claridad. Nos dice que se trata de un presupuesto necesario para explicar la validez, esto es, la existencia de las normas jurídicas. Recuérdese que la validez de una norma no puede derivarse de los hechos (del ser), sino que únicamente puede provenir de otra norma (del deber-ser); de esta manera la norma fundamental es la última norma, de la que se desprende la validez de las otras. Pero presentado de esta manera parece que se trata, simplemente, de una salida dogmática al problema esencial de la validez.

Para acceder a una explicación aceptable del papel que juega la noción de norma fundamental se requiere empezar por tomar en cuenta su contenido, el cual puede expresarse de la siguiente manera: debes obedecer a la constitución $y$, por tanto, a todas las normas que se han promulgado de acuerdo con lo que ella establece. Ello significa que la exigencia de obedecer al derecho no se sustenta únicamente en la amenaza de coacción, sino que, en todos los casos, se exige esa obediencia como un deber. Las condiciones indispensables para que un imperativo sea asumido como un deber son dos: 1) el reconocimiento de los individuos a los que se exige obediencia como personas, es decir, como sujetos que en sus acciones pueden adecuarse o transgredir la norma; de lo contrario esas acciones no les podrían ser imputadas; 2) que en ese imperativo se apela a razones, pues sólo de esa manera el uso de la coacción en caso de una transgresión a la norma (un hecho ilícito) puede considerarse legítima. Uniendo estas dos condiciones, se tiene que la obediencia a las normas constitucionales sólo puede considerarse un deber en la medida que esas normas otorgan derechos a los individuos. De esta manera, se llega a lo que ya se planteaba desde la Declaración de los derechos del ser humano y del ciudadano: "Artículo 16.Toda sociedad que no asegura la garantía de los derechos, ni determina la separación de los poderes, no tiene Constitución".

El sentido de la constitución no puede reducirse a su aspecto jurídicopositivo, esto es, a determinar la organización del poder político y, con ello, a otorgar potestades. El aspecto básico del orden constitucional es el llamado por Kelsen aspecto lógico-jurídico, es decir, la norma fundamental. El problema de la Teoría pura es que no explica de dónde surge el deber de obedecer a la constitución, el cual, como he señalado, sólo puede 
provenir de su capacidad de garantizar los derechos fundamentales. Precisamente, el carácter fundamental de estas normas no se encuentra ni en su forma, ni en el lugar que ocupan, sino en el hecho de que ellas representan la positivación de esa norma suprema. Dicho con otros términos, de los derechos fundamentales emana la autoridad (racional) de la constitución (debes obedecer a la constitución en la medida que ella otorga aquellos derechos fundamentales). En el mencionado artículo 16, el concepto de separación de los poderes denota el orden institucional (el orden concreto) que hace posible garantizar esos derechos.

Al afirmar esto, de ninguna manera se niega la diversidad de constituciones que se encuentran en el nivel empírico. Basta tener presente que el sentido de la constitución define su deber ser, mientras que lo que cada constitución es en su contexto social depende de la correlación de fuerzas que impera en él. El requisito para comprender la relación que existe entre el ser y el deber ser de la constitución consiste en diferenciar el problema de la validez y el tema de la génesis del ordenamiento jurídico. En el nivel abstracto de la validez lo único que se plantea es que la pretensión de autoridad (que presupone su pretensión de validez) de la constitución se sustenta racionalmente en su reconocimiento de los individuos a los que se exige obediencia como seres libres. ¿Puede alguien tener un deber sin ser libre? La libertad es la condición trascendental (condición de posibilidad) del derecho; pero nada garantiza a priori la adecuación entre el sentido de ese sistema social y su realidad.

Una constitución que promueva la mayor libertad humana de acuerdo con leyes que hagan que la libertad de cada uno sea compatible con la de los demás es, como mínimo, una idea necesaria, que ha de servir de base, no sólo al proyecto de una constitución política, sino a todas las leyes [...]. Aunque esto no llegue a producirse nunca, la idea que presenta ese maximum como arquetipo es plenamente adecuada para aproximar progresivamente la constitución jurídica de los seres humanos a la mayor perfección posible (Kant, 1984: 311). 
Al igual que Kant, se puede decir que el derecho fundamental básico es la libertad. Pero este es un principio, es decir, un mandato de optimización, el cual se realiza en distintos grados y con contenidos variables en los distintos contextos sociales. Por tanto, es compatible decir que el principio de la libertad es una condición universal del sentido de la constitución y el asumir que los derechos fundamentales son un artificio que se ha conquistado a través de una larga historia de luchas sociales, que se ha desenvuelto de distintas maneras en los diferentes contextos sociales.

\section{FUENTES CONSULTADAS}

Dippel, H. (2009), Constitucionalismo moderno, Madrid: Marcial Pons.

Elster, J., Slagstad, R. (1999), Constitucionalismo y democracia, México: Fondo de Cultura Económica (FCE).

Fioravanti, M.(2001), Constitución, Madrid: Trotta.

Häberle, P. (2003), El Estado constitucional, México: Instituto de Investigaciones Jurídicas (II)-UnAm.

Heller, H. (1981), Teoría del Estado, México: FCE.

Kant, I. (1984), Crítica de la razón pura, Madrid: Alfaguara.

Kelsen, H. (1979), Teoría general del Estado, México: Editora Nacional. (1986), Teoría pura del derecho, México: unam.

(1995), Teoría general del derecho y del Estado, México: unam.

Lassalle, F. (2002), ¿Qué es una constitución?, Barcelona: Ariel.

Loewenstein, K. (1976), Teoría de la constitución, Barcelona: Ariel.

Luhmann, N. (1993), Das Recht der Gesellschaft, Frankfurt a. M.: Suhrkamp.

MeIer, H. (1994), Die Lehre Carl Schmitts, Stuttgart: Metzler.

Orestes Aguilar, H. (2001), Carl Schmitt, teólogo de la política, México: FCE (selección de textos de C. Schmitt).

Radbruch, G. (2003), Rechtsphilosophie, Heidelberg: C. F. Müller.

SARTori, G. (1992), Elementos de teoría política, Madrid: Alianza.

Schmit, C. (1982), Teoría de la constitución, Madrid: Alianza. (1991), El concepto de lo político, Madrid: Alianza. 
Schmitt, C., Kelsen, H. (2009), El defensor de la constitución y ¿Quién deber ser el defensor de la constitución?, Madrid: Tecnos.

Weber, M. (1982), Escritos políticos, México: Folios. (1983), Economía y sociedad, México: FCE.

Zagrebelsky, G. (2005), Historia y constitución, Madrid: Trotta. (2007), El derecho dúctil, Madrid: Trotta.

Fecha de recepción: 8 de junio de 2011 Fecha de aprobación: 7 de septiembre de 2011 